\title{
Selecting a Research Topic: A Framework for Doctoral Students
}

\author{
Andy Luse, Brian Mennecke, and Anthony Townsend \\ Iowa State University, Ames, IA, USA
}

\author{
andyluse@iastate.edu, mennecke@iastate.edu, amt@iastate.edu
}

\begin{abstract}
This article provides an explanation of the process for selecting a research topic. The article uses Kuhn's classic work on scientific revolutions to delineate the steps in developing theoretical research within an area. The paper provides methods for preparing to develop a research topic, steps for approaching a research problem, as well as methods for problem theoretical development. We end the article with pitfalls that can occur when selecting a research topic as well as bright spots with regard to doctoral students beginning research in an area. Our hope is that this research will help beginning doctoral students start the process of developing a research topic by providing assistance with the overall process.
\end{abstract}

Keywords: research area, topic selection, research type, theory development, research quality

\section{Introduction}

Beginning academic research is one of the most important activities for new doctoral students. While debated by many, the publish or perish mantra still has credence within the academic arena (De Rond \& Miller, 2005). Good teaching may be rewarded locally, and it is a commendable pursuit in and of itself, but most tenure decisions and principles of recognition and prestige are dependent on publication (Bedeian, 1996). Publishing also carries some existential purpose by enabling individuals to leave their mark on the intellectual history of their respective discipline (De Rond \& Miller, 2005). Given the necessity and benefit of academic writing, it is imperative that doctoral students start this process as quickly as possible in their career.

In their manuscript regarding the beginning of the publication process for doctoral students, Stoilescu and McDougall (2010) provide a much needed review for how doctoral students can start the process of publishing early in their academic careers. They provide a useful synopsis of the various steps involved in publishing research, from initiating a project with an idea to submitting and revising the manuscript. One area that the article only briefly addresses is the process of identifying and selecting research topics. While overarching ideas of contribution to the field and the experiential background of the student are mentioned, very little guidance is given as to how

Material published as part of this publication, either on-line or in print, is copyrighted by the Informing Science Institute. Permission to make digital or paper copy of part or all of these works for personal or classroom use is granted without fee provided that the copies are not made or distributed for profit or commercial advantage AND that copies 1 ) bear this notice in full and 2) give the full citation on the first page. It is permissible to abstract these works so long as credit is given. To copy in all other cases or to republish or to post on a server or to redistribute to lists requires specific permission and payment of a fee. Contact Publisher@InformingScience.org to request redistribution permission. to select a research topic. Many doctoral students do not have a research focus, and even those who do may still lack the experience needed to develop a specific topic within a broader research area.

The focus of this article is to explore the process of selecting a research topic and it is intended to function as a prequel to the work of Stoilescu and McDougall on 
publishing academic research (2010). We provide a framework based on the work of Kuhn in his popular work The Structure of Scientific Revolutions (1962). We also provide points on how to prepare for and select research as a doctoral student. The remainder of this manuscript is formatted in sections that help to provide one chronological method to the pursuit of relevant research by the novice academic, supported by the writing of Kuhn. The first section provides introductory techniques and reflections about how to put oneself into the proper mindset for identifying a research topic. The second section describes how one should consider approaching a research problem. Methods of theory development are delineated in the third section. The fourth section describes pitfalls with respect to research while the fifth describes some potential opportunities and benefits. Finally, conclusions are discussed.

\section{Changing Your Mindset}

When setting out to develop a research project, many doctoral students begin by jumping straight to a solution to a problem before they have given the problem adequate thought or sometimes before they even have a well-defined problem at all. This is analogous to the way many novice decision makers approach unfamiliar problems; that is, they focus almost immediately on the solution while ignoring the fundamental steps involved in defining the problem and examining alternatives. The difficulty this presents is that many students are not prepared to engage in the appropriate activities needed to adequately select a research topic based on a defined problem. Before selecting a viable research topic, the individual should become ready mentally to fully engage in the exploration and development process, which can be a challenge for many new doctoral students.

One premise that any researcher must challenge is the acceptance of existing scientific dogma or paradigms (Kuhn, 1962). Many students are indoctrinated in the foundational theories in their discipline because, in essence, from the time of kindergarten students are socialized to accept what they read without significant critical evaluation of what is presented (Davis, 1971; Kuhn, 1962). This training leaves the student inattentive to things to which they should be attentive (Davis, 1971) and traps the student in the routinized, take-it-for-granted way of viewing the world around them (Garfinkel, 1967). To prepare oneself for identifying a research topic, a student should be willing to challenge previously held beliefs. While this can be difficult, there are some techniques that a student can use to foster creative thinking.

1. Brainstorming: When reading and reflecting on research, write down ideas that may not make complete sense. (This points towards the usefulness of carrying a research notebook in which ideas can be recorded.)

2. Outside the discipline: Try to think outside your discipline and training in your academic area. This is often accomplished by questioning assumptions; that is, asking what would be true if we did not have any preconceptions or assumptions.

3. Partner: When thinking of a research topic, run it by someone that is completely out of your area. A good idea is something that makes for a good story. If you can explain the idea to a "layman" or a person outside your field and have it make sense, it is more likely that your idea is logically sound.

4. Ask "Why": Continually ask both yourself and others the question "Why?" By having a partner outside your area ask why, he or she may challenge some issues that you have taken for granted from within your discipline.

5. Talk about it: If you talk an idea through, you will find that you conceptualize the how's, the why's, the where's, the who's, etc. Often we think we understand a problem, but talking about it forces us to piece loosely knit ideas into a cohesive package. 
6. Drawing is fun and effective: While not all research can be visualized, often concepts can be drawn. Graphical representations help you collapse complex ideas into manageable nuggets that can be more easily understood. For most models, if you can draw it you can understand it. In addition, the very model that is drawn may raise new issues to be addressed.

7. Think of things you are interested in: These ideas could be within your area of research or completely unrelated. Good research starts with what the author is interested in, thus buffering against becoming discouraged and uninterested in the research later in the process.

\section{Approaching the Problem}

After the researcher is in a proper mindset, he or she can begin to approach the research problem. One issue many beginning doctoral students have is the idea of actually working on the problem itself. Many novice researchers are more inclined to jump straight into finding solutions to the problem, rather than investing the time needed to dig into the background issues related to the problem. The risk that this strategy creates is that the researcher will not fully understand the problem and, in turn, might fail to recognize fundamental issues that frame the context of the problem. Kuhn (1962) delineates three methods for approaching a problem that allow the researcher to more fully understand the problem before attempting to develop and implement solutions:

- Isolate and give structure

- Magnify the problem

- Search for theory

\section{Isolate and Give Structure}

Most problems that a doctoral student will analyze are not simple; that is, they are parts of complex systems that have component parts, as well as interactions with a broader environmental system. Thus, most research problems will be multidimensional. Of course, a daunting challenge that most investigators face when they try to understand complex questions is taking the entirety of the problem in at once. While having a general top-level understanding of the problem is quite beneficial, sooner or later the researcher must investigate his or her problem's context. First, the researcher should isolate the problem from other external factors to gain a greater understanding of the problem itself. Next, the researcher should specify and define concepts within the problem (Amundson \& Cummings, 1997; Reynolds, 2007). This allows the researcher to understand each component of the problem in isolation before beginning to understand these individual components in greater detail (see magnification below) or integrating these components. Next, the researcher can clarify levels of reference, like part-whole or micro-macro concepts (van de Ven, 1989), before specifying relationships between key concepts (Sutton \& Staw, 1995) and organizing and categorizing these concepts into an overarching typology (Reynolds, 2007). By isolating the parts of the problem the researcher will develop a more thorough understanding before continuing to other tasks, such as problem integration.

\section{Magnify the Problem}

After isolating a problem and giving it structure, the next step is for the researcher to magnify the problem (Kuhn, 1962). By magnifying or elaborating (Bourgeois, 1979) the theoretical basis behind the problem, the researcher can gain a better understanding of the problem itself. While isolation breaks the problem apart into its constituent parts, magnification focuses on a particular isolated section or sections and amplifies every portion of this section to allow for a more thor- 
ough understanding of that particular isolated piece of the problem. Problem sections should be thoroughly magnified to be fully understood by the researcher. This may involve reading about the problem portion, performing experiments to reproduce the problem portion, or merely thinking more thoroughly about the problem portion (e.g., thought experiments). The key is to accent the parts of the individual problem so they are more understandable and easier to grasp.

\section{Search for Theory}

The final step in approaching a problem is to apply one or more relevant theories (Kuhn, 1962) by conducting a complete review of the literature (Bourgeois, 1979). Doctoral students are typically accustomed to conducting literature reviews because this is often one of the first "research" tasks they are given as doctoral students. Nevertheless, this familiarity can be a liability if a thorough and appropriate search is not undertaken. Several guidelines should be considered when conducting a literature review. First, the search should be targeted. While I often find interesting ancillary articles when doing a general search, the researcher should stay on target lest he or she become overwhelmed by the quantity of literature that likely will be found. Next, seminal articles in the domain of investigation should be identified. These articles often represent the "breakthrough" research or a conceptual paper that defines a research stream. Such articles can often be used as a starting point for the search for theoretical concepts associated with the research topic. Working from a seminal article, both references in the article and references to the article should be examined. The primary goal of a thorough literature review is to find sufficient relevant theory and research to formulate a well-structured argument from which your particular research questions can stem. A more detailed summary of conducting a literature review can be found in Levy and Ellis (2006).

\section{Theory Development}

There exist many different ways to develop theory addressing research problems, but many beginning doctoral students find this process daunting. While, on occasion, a research idea can "magically" appear through epiphany (Stoilescu \& McDougall, 2010), most research ideas are derived as a result of a significant investment of time and mental energy. The key is to be ever vigilant about the opportunities and possibilities for new research that will present themselves in unexpected ways and at unanticipated times.

One choice to be made when developing a theoretical base for a problem is the type of theory development methodology to utilize. A theoretical basis can be intricate in detail and pertain to an area that is already established or it can be completely novel and address new or emerging domains. Weick (1969) offers his metaphor of a clock face as one way to look at developing theoretical background for research, claiming that research is a tradeoff between accuracy, simplicity, and generality. Weick posits that any theory will, at most, be strong in two of the three areas on the clock while forgoing the third. Woodside (2010) also developed his cube as an extension of Weick to better delineate different types of theories with theory being a tradeoff between eight different approaches. While these examples offer a helpful guide to developing research, a more detailed guide is typically required for most beginning doctoral students.

A second element important to researchers, and particularly relevant for beginning researchers, is the concept of making a contribution to knowledge. Contribution to knowledge implies an increase in our understanding of a phenomenon so as to contribute to the overall body of knowledge in the area (Creswell, 2005; Leedy \& Ormrod, 2005). Several methods are available by which original research contributions can be made, including establishing causal relationships, evaluating the efficacy of a particular approach to a problem, looking at the problem longitudinally, exploring an approach to address a problem through a descriptive study, establishing a method to create a solution to a problem, developing constructs regarding the causes or characteristics of a 
problem, or developing a predictive model (Ellis \& Levy, 2008). The importance lies in demonstrating there is a contribution to knowledge that creates a step forward in the particular branch of the researcher (Walliman, 2005).

Kuhn (1962) suggests that there are three types of theory development opportunities that can be used to guide researchers. These three methods can be used to develop an underlying theoretical basis for solving a problem. They include:

- New theory about something already explained

- Theory about a known phenomenon, but not about the details

- Anomalies to the existing paradigm

\section{New Theory about Something Already Explained}

Any discipline that includes doctoral study will have a background of literature that is relevant to the field. This theory provides the bedrock for many of the seminar courses that are required for students in doctoral programs. These foundational theories and concepts are usually imparted to students from textbooks in undergraduate programs (Kuhn, 1962) and this knowledge is further built upon in doctoral education during seminars and other core classes. Doctoral students typically find an area within their field and engage in efforts to build extensive literature reviews (Stoilescu \& McDougall, 2010). Given this, doctoral students become fairly well versed in a specific area within the discipline and the foundational theories and research that accompany this domain.

Much research and science starts from a currently understood and generally accepted area, and from there the research effort involves activities that focus on delving into the topic in more depth (Kuhn, 1962). There are many advantages to this type of research. First, it allows the researcher to utilize knowledge he or she has already gained and build from this bedrock. Second, this type of research allows the researcher to examine smaller or more subtle topics within the area that have not yet been investigated (Kuhn, 1962). Also, this allows the researcher to develop more precise techniques to measure a phenomenon (Kuhn, 1962). Bourgeois (1979) argues that greater substantive middle-range theories must be developed that will focus on producing practical results that can be utilized in the field. Without refinement and further development of current research, improvements to current practice will occur less frequently.

While new theories about existing research are needed, there are also drawbacks to this type of theoretical background development for research. First, if a researcher delves into an existing research stream hyper-extensively, sometimes the research will no longer be accessible by a general audience (Kuhn, 1962). Also, this type of theoretical development runs the risk of culminating in research that is merely description of small-scale or inconsequential phenomena (Bourgeois, 1979). Furthermore, this type of research, if not checked, can culminate in counting things for the sake of counting or generating data primarily for the purpose of applying rigorous statistical techniques (Bourgeois, 1979). While new theories about explained phenomena are needed, these theories run the risk of regressing into non-interesting research that only affirms the assumptions of their audience (Davis, 1971).

\section{Theories about a Known Phenomenon, but Not about the Details}

Some areas within a discipline can be known, but not well understood. Many researchers want to solve the puzzles that no one else has been able to solve in the area, but many times a researcher must settle for adequately describing the problem and leave further analysis for others (Kuhn, 1962). This type of research will classify phenomena without expounding on the details that lie below the surface (Lewin, 1965) and can be used to provide a roadmap for future research in the area (Kuhn, 1962). Doctoral students are in a unique situation here because they are beginning to 
synthesize research in a particular area for future work towards their dissertation. Doctoral students, during these initial forays in the field, build a literature review and, as an outcome, this review can provide a taxonomy of some area that is original in its synthesis of ideas (Stoilescu \& McDougall, 2010). This synthesis may not provide the details, but a much needed infusion of new or innovative ideas into the field.

Some authors argue that a greater number of conceptual theoretical bases are needed before tackling the big problems in a discipline. These "middle-range" theories are needed to help guide empirical inquiry (Merton, 1968) and can be used to formally compare current research to yield more general taxonomies (Glaser, 1968). In fact, the argument has been made that some areas are not yet ready for more "all-encompassing" theories because the necessary preparatory work has yet to be done (Merton, 1968). This implies that more research should be conducted that explores a known phenomenon at a high level, even if the details may not be known.

Given the above arguments in favor of higher-level theoretical bases for research problems, there are still some counter-arguments, particularly as it pertains to publishing. Some journal editors look at this type of research as mundane or unoriginal while other editors disagree with this assessment and are prone to evaluate the article based on its fundamental contribution to the field (Levy \& Ellis, 2006; Stoilescu \& McDougall, 2010). Whether or not this type of research is publishable represents a separate issue from the fact that it can offer a good start to inquiry in an area and can provide a framework from which to springboard to more research.

\section{Anomalies to Existing Research}

Anomalies in existing research can both offer promise and simultaneously instill reticence for researchers. For example, Kuhn (1962) points out that anomalies can open new doors while also casting doubt on previous research. Many researchers are cautious when it comes to irregularities between current and previous research because of the perception that they run the risk of being criticized for questioning orthodoxy.

Kuhn (1962) and others argue that the best type of research occurs when it contradicts existing research by providing a viable alternative to what is accepted as the status quo. Davis (1971) argues that new theoretical development is more pronounced and, as a result, more likely to be noticed when it falsifies an established "truth.” Davis (1971) bases an entire article on delineating "interesting" research on the presupposition that this research challenges currently held truths. He argues that an interesting proposition is always the negation of an accepted one and a new proposition will be noticed only when it runs counter to an established truth. These types of anomalies create tensions, inconsistencies, and contradictions between accepted research and new research that provide opportunity to develop better theoretical bases for, and draw attention to, your research (van de Ven, 1989). Given this, research that examines or highlights anomalies in existing research represents a rich area for study. Of course, the process of developing research that reflects these qualities is not easy. Weick (1989) offers a description of "disciplined imagination" to aid in theoretical development to problem solving that consists of defining the three components of a problem: the problem statement, thought trials, and selection criteria. Davis (1971) also details a number of methods for finding interesting research, many of which challenge currently held beliefs in the field. While finding anomalies may be a daunting task, there are ways of leveraging these opportunities to develop new and exciting research through practice.

\section{Pitfalls}

Research offers the potential for a great number of rewards for both the researcher and society at large, but there are also potential hazards in the process outlined here for selecting a suitable research topic. Here we list some of the pitfalls which can be associated with this process. 
Above, the first change in mindset put forth was that of questioning past scientific learning. This is a very beneficial endeavor and one that doctoral students should learn, but as with everything, a proper balance should be maintained. If you examine every anomaly, you will never get any work done (Kuhn, 1962). One of the challenges of becoming a good researcher is parsing those research questions that are important enough to be examined from those that should not be questioned. Put another way, one ought to be able to identify those problems that have promise and have practical import. The criteria for making this decision will be unique for different researchers in different research areas, but they should be discovered and evaluated by each individual both through reason and through experience. Of course, experience only comes when one is willing to take the risk to make mistakes.

Another potential pitfall is choosing to work with or reference "corroborated" research over noncorroborated research (Kuhn, 1962). Many doctoral students - and seasoned researchers for that matter - are drawn to "reputable" theories often because of the amount of corroboration, the strength of citations in the literature, the theory's popularity, etc. While this is a very pragmatic approach, this research should not be the end-all when performing research. There is good research out there that is new or un-examined that offers potential for research due to its unpopularity or novelty. Remember that even Einstein's theory of relativity (1916) was rarely cited in 1916.

\section{Bright Spots}

The previous section identified some of the pitfalls of theory development. There are also bright spots for doctoral students as they begin to develop their own theoretical research agendas. While everyone will not realize these potential advantages, they do offer some ideas for approaching your research in a manner that could increase the possibility of producing novel, interesting research.

Kuhn (1962) points out that those who are new to a field feel less tied to a specific worldview or paradigm of research. This provides many opportunities for doctoral students. First, since those new to a field are less tied to the previous research in a field, they have the potential to make the biggest discoveries because they are more open-minded (Kuhn, 1962). While those entrenched in the theories that predominate in a field seldom question previous research upon which they base their own research, those who are new to research will have fewer of these strongly held views. This is why changing your mindset to question previous research is so important. Doing this will allow the researcher to think outside the box and potentially make discoveries that are unavailable to more seasoned researchers due to their faith in the research area's background literature.

Another bright spot is the ability to approach a problem from a different area/paradigm. Good science often arises, almost by accident, when someone outside the field questions the status quo and looks at a problem from an open-minded perspective (Kuhn, 1962). A new doctoral student, being less tied to a specific field, is more open to viewing a problem from the vantage point of another area. Applying knowledge or theories from other disciplines may open the door to solving problems within the home discipline in new and exciting ways.

\section{Conclusion}

Many times the act of selecting a research topic is overlooked in the overall process of publishing academic research. This manuscript addresses this problem by providing a much needed delineation of the steps that are involved in the selection of a research topic. The analysis presented here is designed to be used as a prequel to the work of Stoilescu and McDougall (2010) See Figure 1 for the specifics of how this work adds to that of Stoilescu and McDougall. 
- The Initial Start: Building Momentum

o The Awakening Act and the Warming up Process

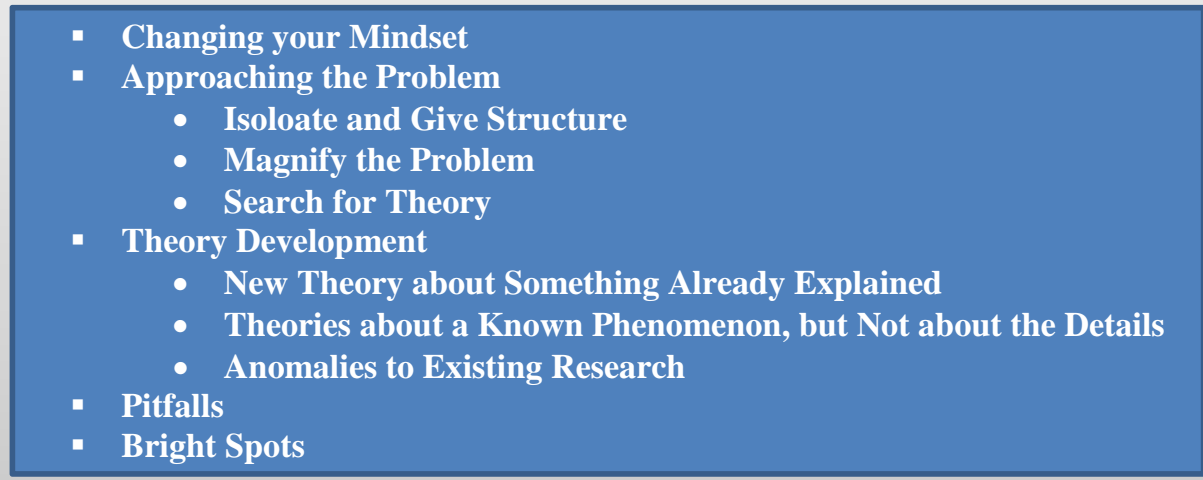

o Selecting an Adequate Journal

- Opportunities to Publish Academic Research

- Social Aspects to Consider When Writing

- Policies and Ethical Issues in Academic Publishing

- Submitting and Publishing Scholarly Manuscripts

Figure 1. Table listing of work by Stoilescu and McDougall (2010) with our added work shown in the square.

One final comment we feel needs greater explanation is on the topic of "extraordinary" research. Many authors, including those cited in this work, have opinions as to what extraordinary research entails. Davis (1971) claims that the only interesting research is that which tries to explain something by contradicting the assumptions of the intended audience of the paper. Merton (1968) claims that, in certain fields, middle-range theories are more important because all-encompassing theories are generally not feasible. Woodside's (2010) box implies that the central triangulation method of theoretical research is somehow superior. Even Kuhn himself (1962) suggests that theories that try to explain anomalies in existing research are more exemplary. While some of these "ideal" types of theories may be more publishable in certain academic journals, this manuscript does not claim that one type of theory is inherently superior to another. Instead, we have concentrated on providing practical guidance that doctoral students can leverage to better develop their own theories using whatever theoretical type they prefer.

\section{References}

Amundson, S. D., \& Cummings, L. L. (1997). Organizational vision through the lens of quality: A framework for integration of quality management and organizational behavior. In D. Fedor \& S. Ghosh (Eds.), Advances in the management of organizational quality (Vol. 2, pp. 251-288). Greenwich, CT: JAI Press.

Bedeian, A. G. (1996). Lessons learned along the way: Twelve suggestions for optimizing career success. In P. J. Frost \& M. S. Taylor (Eds.), Rhythms of academic life: Personal accounts of careers in academia (pp. 3-9). Thousand Oaks, CA: Sage.

Bourgeois, L. J., III. (1979). Toward a method of middle-range theorizing. The Academy of Management Review, 4(3), 443-447.

Creswell, J. W. (2005). Educational research: Planning, conducting, and evaluating quantitative and qualitative research (2nd ed.). Upper Saddle River, NJ: Pearson.

Davis, M. (1971). That's interesting!: Towards a phenomenology of sociology and a sociology of phenomenology. Philosophy of the Social Sciences, 1(2), 309-344.

De Rond, M., \& Miller, A. N. (2005). Publish or perish. Journal of Management Inquiry, 14(4), 321-329. 
Einstein, A. (1916). Relativity: The special and general theory. New York: H. Holt and Company.

Ellis, T. J., \& Levy, Y. (2008). Framework of problem-based research: A guide for novice researchers on the development of a research-worthy problem. Informing Science: the International Journal of an Emerging Transdiscipline, 11, 17-33.

Garfinkel, H. (1967). Studies in ethnomethodology. Malden, MA: Blackwell Publishing.

Glaser, B. G. (1968). Organizational careers: A sourcebook for theory. Chicago: Aldine.

Kuhn, T. S. (1962). The structure of scientific revolutions. Chicago: University of Chicago Press.

Leedy, P. D., \& Ormrod, J. E. (2005). Practical research: Planning and design (8th ed.). Upper Saddle River, NJ: Prentice Hall.

Levy, Y., \& Ellis, T. J. (2006). A systems approach to conduct an effective literature review in support of information systems research. Informing Science Journal, 9, 181-212. Retrieved from http://www.inform.nu/Articles/Vol9/V9p181-212Levy99.pdf

Lewin, K. (1965). Formalization and progress in psychology. In Lindzey \& Hall (Eds.), Theories of personality (pp. 201-215). New York: John Wiley.

Merton, R. K. (1968). Social theory and social structure (enlarged ed.). New York: Free Press.

Reynolds, P. (2007). A primer in theory construction. Boston: Pearson Education.

Stoilescu, D., \& McDougall, D. (2010). Starting to publish academic research as a doctoral student. International Journal of Doctoral Studies, 5, 79-92. Retrieved from http://ijds.org/Volume5/IJDSv5p079-092Stoilescu299.pdf

Sutton, R. I., \& Staw, B. M. (1995). What theory is not. Administrative Science Quarterly, 40(3), 371-384.

van de Ven, A. H. (1989). Nothing is quite so practical as a good theory. The Academy of Management Review, 14(4), 486-489.

Walliman, N. (2005). Your research project (2nd ed.). London: Sage Publications.

Weick, K. E. (1969). The social psychology of organizing. Reading, MA: Addison-Wesley.

Weick, K. E. (1989). Theory construction as disciplined imagination. The Academy of Management Review, 14(4), 516-531.

Woodside, A. G. (2010). Case study research: Theory, methods, practice. Bingley, United Kingdom: Emerald Group.

\section{Biographies}

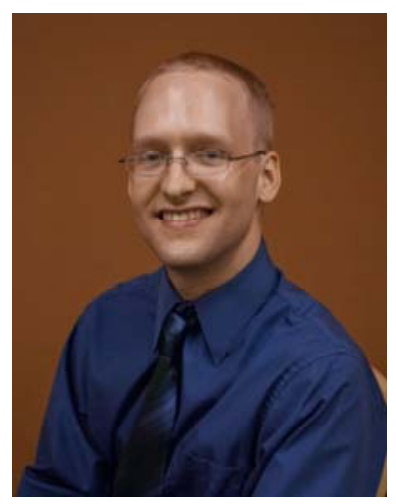

Andy Luse is a PhD student in Business and Technology specializing in Management of Information Technology at Iowa State University. Andy received his Ph.D. in Human Computer Interaction and Computer Engineering from Iowa State University. His research interests include computer and network security, visualization for computer and network security, and statistical methodology. He is currently involved in research surrounding interest in Information Technology as a major among high school students through incorporation of the ITAdventures program. 


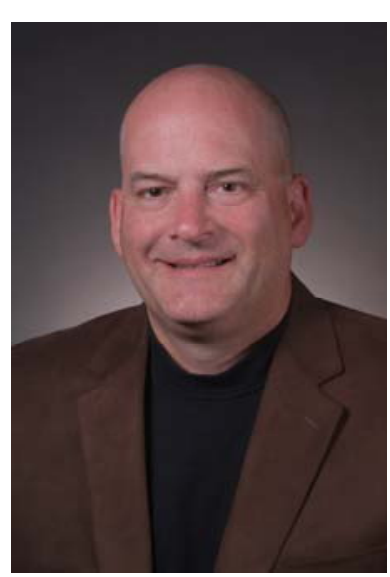

Brian E. Mennecke is an Associate Professor of Management Information Systems at Iowa State University. His research interests include collaboration and collaborative systems, social media and virtual worlds, embodiment and perceptions of space, security systems and biometrics, mobile and electronic commerce, and spatial technologies. He has previously published a book on mobile commerce and articles in academic and practitioner journals such as Management Information Systems Quarterly, the Decision Sciences Journal, the International Journal of Human-Computer Studies, the Journal of Management Information Systems, Organizational Behavior and Human Decision Processing, the International Journal of Human Computer Studies, the Journal of Information Privacy and Security, and the Journal of Digital Forensics, Security \& Law.

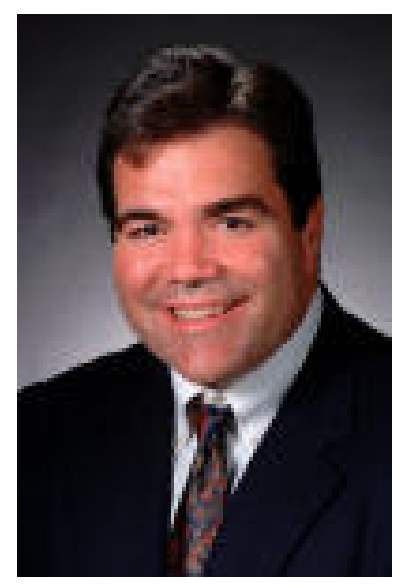

Anthony M. Townsend is an Associate Professor of MIS at Iowa State University. He received his M.S. and Ph.D. from Virginia Polytechnic Institute and State University and conducts research in collaborative systems and virtual teams. He has published in MIS Quarterly, Information Systems Research, and the Communications of the ACM, among other venues. He is currently conducting research in collaborative systems designed to enhance a variety of organizational processes, including security. 